\title{
Self-Excited Vibration During Slippage of Parallel Cardan Drives for Electric Railcars*
}

\author{
Tetsuji HIROTSU**, Shooji KASAI** \\ and Hideo TAKAI***
}

\begin{abstract}
Detailed digital simulations and eigenvalue analyses of self-excited vibration during slippage of parallel Cardan drives were made. The effects of the stiffness and damping of flexible couplings and gearbox suspension rubber springs were studied, and measures to suppress the self-excited vibration were clarified. Experiments involving two cases of a leaf spring coupling were made by varying the stiffness and damping of the coupling and the gearbox suspension rubber spring. The results agreed well with theoretical results. Experiments for a third case with a gear coupling were also made. This case generated less vibration. Furthermore, the available adhesion coefficient $\mu_{a}$ (average total tractive effort/total driving axle load) was measured for two cases with and without self-excited vibration, and it was shown that the latter case could attain a larger $\mu_{a}$.
\end{abstract}

Key Words : Electric Railcars, Parallel Cardan Drives, Self-excited Vibration during Slippage, Wheel-Rail Adhesion, Leaf Spring Couplings, Gear Couplings

\section{Introduction}

In the past few years, electric railcars equipped with induction motors for traction have been developed. One advantage of these cars is that better adhesion performance is attained by the constant speed characteristic that is inherent in the induction motors. This characteristic rapidly decreases traction motor torque and allows slip speed to be suppressed to a very low level. Thus, these cars are often operated at a continuous low slip speed, especially on wet rails. Self- excited vibration, i.e. vibration attributed to the negative damping friction between the wheel and the rail during slippage, in the drive system occurs easily under these conditions. Suppressing the self-excited vibration is desirable because its generation causes excessive stress in the drive system, which prevents the utilization of its excellent adhesion performance.

* Received 21st November, 1986. Paper No. 86-0132A

** Hitachi Research Laboratory, Hitachi Ltd., Katsuta, Ibaraki, 312, Japan

*** Kasado Works, Hitachi Ltd., Kudamatsu, Yamaguchi, 744, Japan
Several papers have been published ${ }^{(1),(2)}$ in which the occurrence of self-excited vibration in induction motor-type locomotives was reported. Work has also been published on digital simulations of the selfexcited vibration in locomotive drive systems ${ }^{(3)}$.

One of the authors has previously investigated the self-excited vibration in locomotive trucks during slippage ${ }^{(4)}$. This previous study examined the comparatively lower frequency vibrations due to the action of cushion springs that were inserted into the drive system.

The present paper describes a detailed theoretical study regarding the self-excited vibration during slippage on the parallel Cardan drive, the drive most often used in electric railcar trucks. This study took into consideration the spring constants for axles and gears, besides cushion springs, so that methods to suppress all frequency components of the self-excited vibration could be found. Then, experiments were made to evaluate the theoretical methods. The available adhesion coefficients with and without the selfexcited vibration were also measured. 


\section{Theoretical Studies}

\section{1 Digital simulations}

Leaf spring couplings and gear couplings are most frequently used as flexible couplings in railcars. There are two couplings based on the leaf spring coupling principle, as shown in Figs. 1 (i) and (ii). In the former, a leaf spring is attached to each end of a torsion shaft that has been inserted into the hollow section of a hollow motor rotor. In the latter, which has a solid motor rotor, a short-leaf spring coupling is installed between the traction motor and pinion. In the gear coupling-type of Fig. 1 (iii), a gear coupling is mounted between the solid motor rotor and pinion.

Figure 2 shows a dynamic model of a parallel Cardan drive. It is applicable to either flexible coupling. The motor generates a drive torque, which passes through the flexible coupling to the pinion, from the pinion to the gear wheel, and then from the gear wheel, through the axle to the left and right wheels. The traction motor is attached to the truck frame. The gearbox suspension rubber spring and the flexible coupling absorb the vertical relative displacement between a gear wheel which is attached to the axle and the traction motor. In deriving the model, consideration is given to the spring action of the motor rotor shaft containing the torsion shaft, the pinion shaft, the gear teeth, the axle, the gearbox suspension rubber

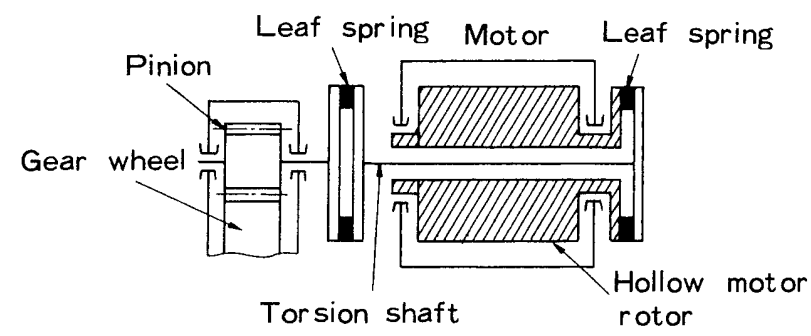

(i) Leaf spring coupling (1)

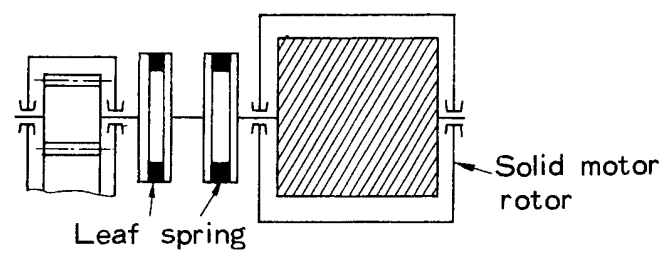

(ii) Leaf spring coupling (2)

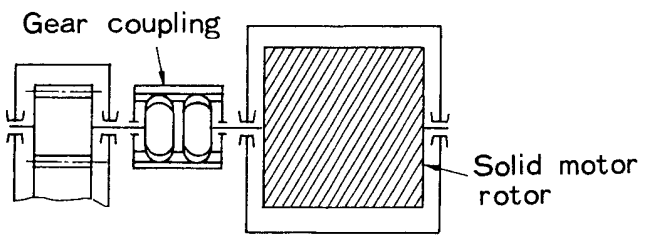

(iii) Gear coupling

Fig. 1 Representative flexible couplings spring, and damping in the motor rotor shaft and gearbox suspension rubber spring.

Slippage occurs when the wheel drive force (wheel drive torque/wheel radius) exceeds the adhesion limit. For simplicity, the car speed is assumed to be zero; then the basic equations for slippage are as follows :

$$
\begin{aligned}
& I_{m} \ddot{\theta}_{m}+C_{m}\left(\dot{\theta}_{m}-\dot{\theta}_{c}\right)+k_{m}\left(\theta_{m}-\theta_{c}\right)=\tau_{m} \\
& I_{c} \ddot{\theta}_{c}-C_{m}\left(\dot{\theta}_{m}-\dot{\theta}_{c}\right)-k_{m}\left(\theta_{m}-\theta_{c}\right) \\
& \quad+k_{p}\left(\theta_{c}-\theta_{p}\right)=0 \\
& I_{p} \ddot{\theta}_{p}-k_{p}\left(\theta_{c}-\theta_{p}\right) \\
& \quad-r_{p} k_{t}\left(r_{g} \theta_{g}-r_{p} \theta_{p}+l_{1} \theta_{s}\right)=0 \\
& I_{g} \ddot{\theta}_{g}+r_{g} k_{t}\left(r_{g} \theta_{g}-r_{p} \theta_{p}+l_{1} \theta_{s}\right) \\
& \quad+k_{w 1}\left(\theta_{g}-\theta_{w 1}\right)+k_{w 2}\left(\theta_{g}-\theta_{w 2}\right)=0 \\
& I_{w} \ddot{\theta}_{w 1}=A_{1}\left\{k_{w 1}\left(\theta_{g}-\theta_{w 1}\right)-B_{1} \mu_{s 1} W r_{w}\right\} \\
& I_{w} \ddot{\theta}_{w 2}=A_{2}\left\{k_{w 2}\left(\theta_{g}-\theta_{w 2}\right)-B_{2} \mu_{s 2} W r_{w}\right\} \\
& I_{s} \ddot{\theta}_{s}+l_{1} k_{t}\left(r_{g} \theta_{g}-r_{p} \theta_{p}+l_{1} \theta_{s}\right) \\
& \quad+l_{2}^{2} C_{s} \dot{\theta}_{s}+l_{2}^{2} k_{s} \theta_{s}=0 \\
& T \dot{\tau}_{m}+\tau_{m}=\tau_{m 0}-\rho \dot{\theta}_{m}
\end{aligned}
$$

where

$\theta_{m}, \theta_{c}, \theta_{p}, \theta_{g}, \theta_{w i}, \theta_{s}:$ Angular displacements of the traction motor rotor, flexible coupling, pinion, gear wheel, axle, and gearbox

$I_{m}, I_{c}, I_{p}, I_{g}, I_{w} I_{s}$ : Moments of inertia of the traction motor rotor, flexible coupling, pinion, gear wheel, axle, and gearbox

$k_{m}, k_{p}, k_{t}, k_{w i}, k_{s}$ : Spring constants of the motor rotor shaft, pinion shaft, gear teeth, axle, and gearbox suspension rubber spring

$C_{m}, C_{s}$ : Damping coefficients of the motor rotor shaft and the gearbox suspension rubber spring

$r_{p}, r_{g}:$ Pitch circle radii of the pinion and the gear

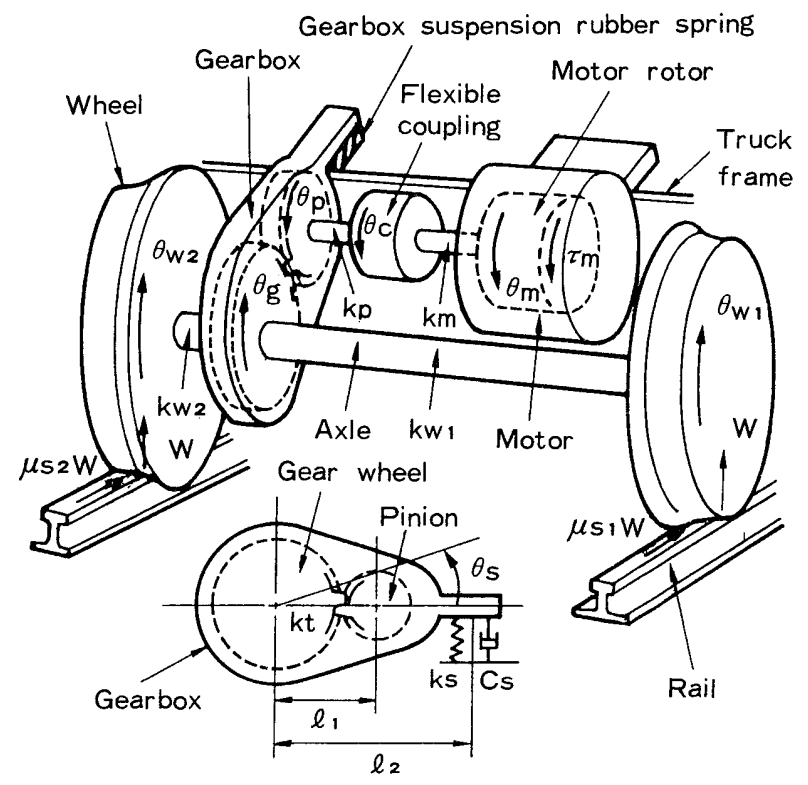

Fig. 2 Dynamic model of a parallel Cardan drive 
wheel

$l_{1}$ : Distance between the gear wheel and pinion centers

$l_{2}$ : Distance between the axle and gearbox suspension rubber spring centers

$\mu_{s i}$ : Friction coefficient between the wheel and rail

$W:$ Wheel load

$r_{w}$ : Wheel radius

$\tau_{m}$ : Traction motor torque

$\tau_{m 0}$ : Traction motor torque at adhesion limit

$\rho:$ Ratio of traction motor torque to increasing angular velocity of traction motor rotor

$T:$ Time constant of response in traction motor torque

$A_{i}, B_{i}$ : Variables for simulating discontinuity in the friction coefficient

Subscripts $i=1, i=2$ denote right and left sides of the gear wheel, respectively.

The friction coefficient $\mu_{s i}$ between the wheel and rail is related to slip speed in Fig. 3 . When the traction motor torque $\tau_{m}$ is at the level of the adhesion limit $\tau_{m 0}\left(=2 \mu_{0} W r_{w} r_{p} / r_{g}\right)$, the adhesion coefficient decreases stepwise by the amount $\Delta \mu_{i}$ to produce slippage.

The friction coefficient is derived by the following equation.

$$
\mu_{s i}=\mu_{0}-C_{2}-\Delta \mu_{i}+\frac{C_{2}}{1+C_{1} r_{w}\left|\dot{\theta}_{w i}\right|}
$$

Here, $C_{1}$ and $C_{2}$ are constants for approximating the characteristics in Fig. 3.

The variables $A_{i}$ and $B_{i}$ are structured and determined so that, as Fig.3 indicates, the friction coefficient $\mu_{s i}$ is discontinuous at $\dot{\theta}_{w i}=0$.

$$
\begin{array}{lll}
A_{i}=1, B_{i}=1 & \text { (when } & \left.\dot{\theta}_{w i}>0\right) \\
A_{i}=1, B_{i}=-1 & \text { (when } & \left.\dot{\theta}_{w i}<0\right) \\
A_{i}=0 & \text { (when } & \left.\dot{\theta}_{w i}=0\right)
\end{array}
$$

When $\dot{\theta}_{w i}=0$, the following discriminations are needed:

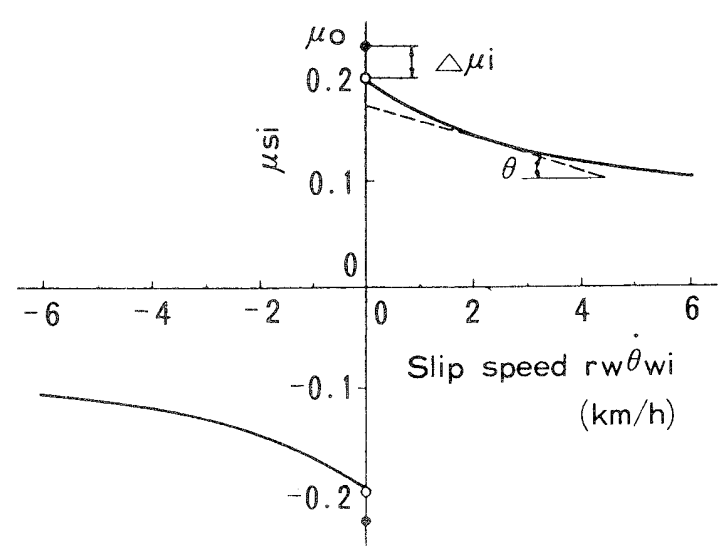

Fig. 3 Relationships between slip speed and friction coefficient

$$
\begin{aligned}
& \text { if }\left|k_{w i}\left(\theta_{g}-\theta_{w i}\right)\right|<\mu_{0} W r_{w}, \text { then } A_{i}=0 \quad\left(\dot{\theta}_{w i}=0 \quad\right. \text { con- } \\
& \text { tinues) } \\
& \text { if } k_{w i}\left(\theta_{g}-\theta_{w i}\right) \geqq \mu_{0} W r_{w}, \text { then } A_{i}=1, B_{i}=1 \text { (slipp- } \\
& \text { age occurs again in the posi- } \\
& \text { tive direction) }
\end{aligned}
$$

if $k_{w i}\left(\theta_{g}-\theta_{w i}\right) \leqq-\mu_{0} W r_{w}$, then $A_{i}=1, B_{i}=-1$ (slippage occurs again in the negative direction)

Because $\dot{\theta}_{w i}=0$ cannot be satisfied in actual numeric computations, $B_{i} \cdot \dot{\theta}_{w i} \leqq 0$ is regarded as $\dot{\theta}_{w i}=0$.

Assuming that the initial conditions at time $t=0$ are such that the traction motor generating torque is equivalent to the adhesive limit and is in an equilibrium state, the time history of each variable can be derived by digital computation using the RungeKutta-Gill method.

Using the numerical values in Table 1, digital simulations were made, based on the basic equation cited above. A parallel Cardan drive for electric rail. cars equipped with a $130 \mathrm{~kW}$ hollow shaft traction motor and leaf spring coupling was used. The item $k_{m}$ (Table 1) was for a $46 \mathrm{~mm}$ diameter torsion shaft, while $k_{s}$ and $C_{s}$ were for a gearbox suspension rubber spring made of natural rubber. These were the same as parts conventionally used. A value for $C_{s}$ was derived with $\varepsilon$ as the loss factor for the rubber spring and $\omega$ as the angular frequency of vibration in the object.

$$
C_{s}=\varepsilon \cdot k_{s} / \omega
$$

For the relation between the slip speed and the friction coefficient, the following values were used, along with the average characteristics obtained by actual measurements as in Fig. 3.

$$
\begin{aligned}
& \mu_{0}=0.23, \Delta \mu_{1}=0.03, \Delta \mu_{2}=0.015 \\
& C_{1}=1.05 \mathrm{~s} / \mathrm{m}, C_{2}=0.148
\end{aligned}
$$

Table 1 Specifications of the drive systems studied

\begin{tabular}{|l|l|l|l|l|l|}
\hline Item & Unit & Value & Item & Unit & Value \\
\hline $\mathrm{Im}$ & $\mathrm{kg} \cdot \mathrm{m}^{2}$ & 3.5 & $\mathrm{ks}$ & $\mathrm{N} / \mathrm{m}$ & $7.8 \times 10^{6}$ \\
\hline $\mathrm{Ic}$ & $\mathrm{kg} \cdot \mathrm{m}^{2}$ & 0.16 & $\mathrm{Cm}$ & $\mathrm{N} \cdot \mathrm{m} \cdot \mathrm{s}$ & 0.0 \\
\hline $\mathrm{Ip}$ & $\mathrm{kg} \cdot \mathrm{m}^{2}$ & 0.01 & $\mathrm{Cs}$ & $\mathrm{N} \cdot \mathrm{s} / \mathrm{m}$ & $1.3 \times 10^{3}$ \\
\hline $\mathrm{Ig}$ & $\mathrm{kg} \cdot \mathrm{m}^{2}$ & 6.0 & $\mathrm{rp}$ & $\mathrm{m}$ & 0.052 \\
\hline $\mathrm{Iw}$ & $\mathrm{kg} \cdot \mathrm{m}^{2}$ & 38 & $\mathrm{rg}$ & $\mathrm{m}$ & 0.329 \\
\hline $\mathrm{Is}$ & $\mathrm{kg} \cdot \mathrm{m}^{2}$ & 16 & $\mathrm{rw}$ & $\mathrm{m}$ & 0.430 \\
\hline $\mathrm{kw} 1$ & $\mathrm{~N} \cdot \mathrm{m}$ & $8.3 \times 10^{6}$ & $\ell$ & $\mathrm{m}$ & 0.381 \\
\hline $\mathrm{kw} 2$ & $\mathrm{~N} \cdot \mathrm{m}$ & $6.8 \times 10^{7}$ & $\ell 2$ & $\mathrm{~m}$ & 0.500 \\
\hline $\mathrm{km}$ & $\mathrm{N} \cdot \mathrm{m}$ & $5.4 \times 10^{4}$ & $\mathrm{~W}$ & $\mathrm{~N}$ & $3.9 \times 10^{4}$ \\
\hline $\mathrm{kp}$ & $\mathrm{N} \cdot \mathrm{m}$ & $2.3 \times 10^{6}$ & $\mathrm{~T}$ & $\mathrm{~s}$ & 0.02 \\
\hline $\mathrm{kt}$ & $\mathrm{N} / \mathrm{m}$ & $1.4 \times 10^{9}$ & $\rho$ & $\mathrm{N} \cdot \mathrm{m} \cdot \mathrm{s}$ & 56 \\
\hline
\end{tabular}


Figure 4( i ) shows digital simulation results. The digital simulations gave the main vibrations as approximately 97 and approximately $20 \mathrm{~Hz}$. Based on the eigenvalue analyses given later, the $97 \mathrm{~Hz}$ component corresponded to the axle torsional vibration, and the $20 \mathrm{~Hz}$ component to the pitching vibration of the gearbox surrounding the axle. The axle torsional vibration, in particular, became an unstable selfexcited vibration. At the point where slip speed was zero, the friction coefficient became discontinuous, which caused it to enter the limit cycle and be restricted to an amplitude that was almost constant.

The damping coefficient $C_{s}$ of the gearbox suspension rubber spring was increased to suppress the self-excited axle torsional vibration, but digital simulations showed that it alone had no effect. This was attributed to the small spring constant $k_{m}$ of the motor rotor shaft, the slight pitching of the gearbox, and the absence of any contribution from $C_{s}$ to suppress the axle torsional vibration. More simulations were then done, assuming an increase in the torsion shaft diame-

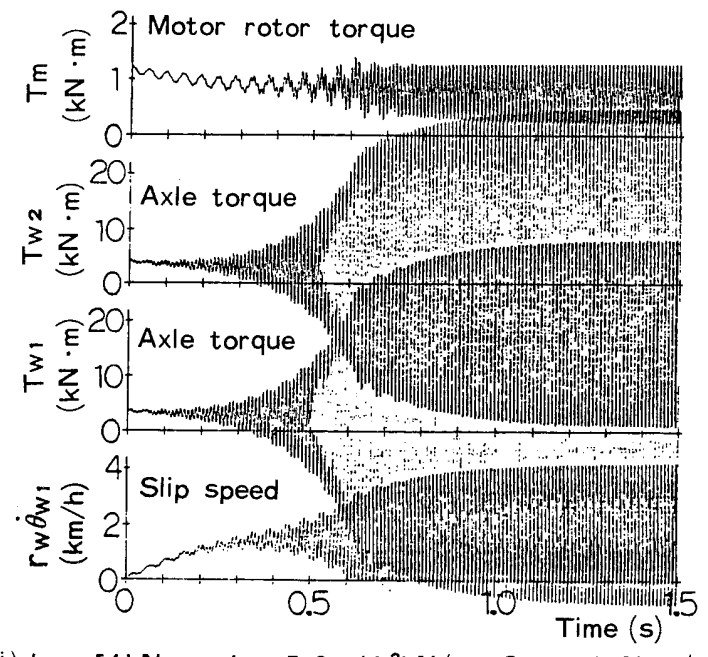

(i) $\mathrm{km}=54 \mathrm{kN} \cdot \mathrm{m}, \quad \mathrm{ks}=7.8 \times 10^{3} \mathrm{kN} / \mathrm{m}, \quad \mathrm{Cs}=1.3 \mathrm{kN} \cdot \mathrm{s} / \mathrm{m}$
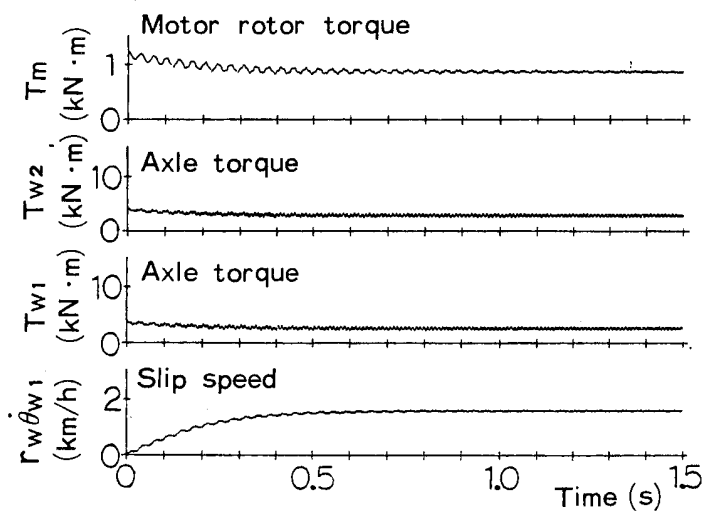

(ii) $\mathrm{km}=88 \mathrm{kN} \cdot \mathrm{m}, \mathrm{ks}=1.8 \times 10^{4} \mathrm{kN} / \mathrm{m}, C s=8.5 \mathrm{kN} \cdot \mathrm{s} / \mathrm{m}$

Fig. 4 Digital simulation results ter to $52 \mathrm{~mm}$ to give $k_{m}=88 \mathrm{kN} \cdot \mathrm{m}$, and using synthetic rubber for the gearbox suspension rubber spring, which had a high loss factor and spring constant, to give $k_{s}=1.8 \times 10^{4} \mathrm{kN} / \mathrm{m}$ and $C_{s}=8.5 \mathrm{kN} \cdot \mathrm{s} / \mathrm{m}$. Fig. 4 (ii) shows the results of these simulations. The self-excited vibration was satisfactorily suppressed.

\section{2 Eigenvalue analyses}

When the relation between the slip speed and friction coefficient between the wheel and the rail is approximately linear, as the broken line in Fig. 3 shows, the following linear equation is obtained to describe the slippage phenomenon.

$$
\boldsymbol{M} \ddot{\boldsymbol{y}}+\boldsymbol{C} \dot{\boldsymbol{y}}+\boldsymbol{K} \boldsymbol{y}=\boldsymbol{F}
$$

Here $\boldsymbol{M}, \boldsymbol{C}$ and $\boldsymbol{K}$ are the matrices for mass, damping and stiffness, and $\boldsymbol{y}$ and $\boldsymbol{F}$ are the displacement and the external force vectors.

Equation 12 was used to perform the eigenvalue analyses.

Taking the spring constant $k_{m}$ of the motor rotor shaft as the parameter for the problem axle torsional vibration, the results of deriving the relationships between the real part of the eigenvalue and the characteristics of the gearbox suspension rubber spring $\left(k_{s}\right.$ and $C_{s}$ ) are those shown in Fig. 5. In this analysis, it would be unrealistic to keep the spring constant $k_{s}$ of the gearbox suspension rubber spring constant and make large changes in the damping coefficient $C_{s}$ only; so a linear change was also made in the spring constant $k_{s}$, in relation to $C_{s}$. The relation between the slip speed and the friction coefficient approximated

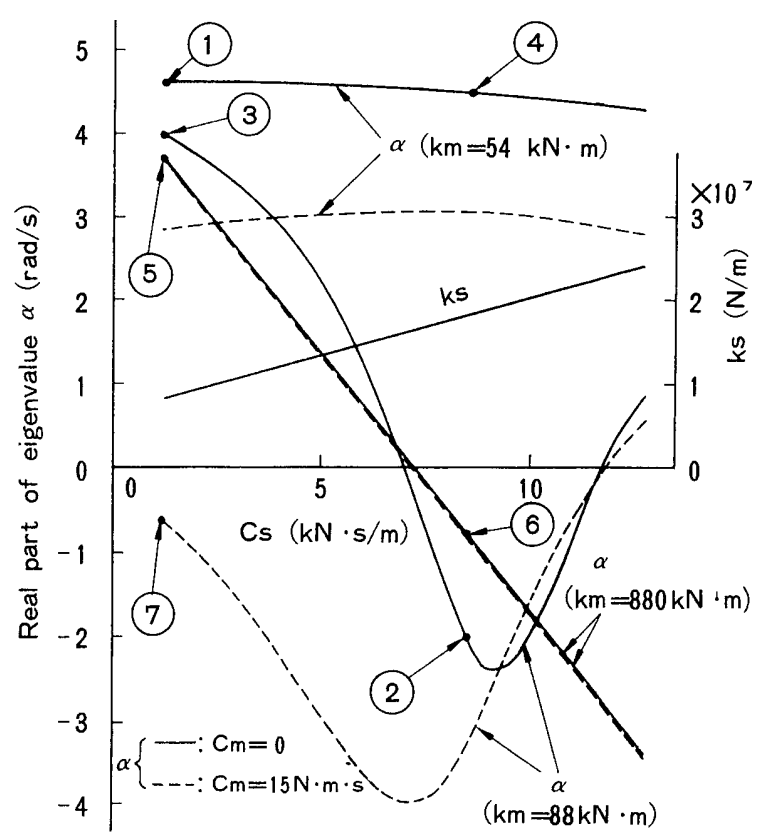

Fig. 5 Relation between $\mathrm{ks}$ and $C_{s}$ and real part of eigenvalues 
linearity, as shown by the broken line in Fig. 3, and $0.052 \mathrm{~s} / \mathrm{m}$ was used as the value of the decreasing ratio, tangent $\theta$.

The results for two damping coefficient $C_{m}$ values are shown in Fig. 5. For $k_{m}=54 \mathrm{kN} \cdot \mathrm{m}$, the situation was equivalent to using a hollow shaft traction motor and leaf spring coupling that had a torsion shaft diameter of $46 \mathrm{~mm}$. For $k_{m}=88 \mathrm{kN} \cdot \mathrm{m}$, the situation was equivalent to using a torsion shaft with a diameter of $52 \mathrm{~mm}$. For $k_{m}=880 \mathrm{kN} \cdot \mathrm{m}$, the situation was equivalent to using a solid shaft traction motor and leaf spring coupling.

When $k_{m}=54 \mathrm{kN} \cdot \mathrm{m}$, the real part $\alpha$ of the eigenvalue showed hardly any change, even when $k_{s}$ and $C_{s}$ increased. Because the value $\alpha$ was positive, the result would be an unstable, self-excited vibration. However, when $k_{m}=88 \mathrm{kN} \cdot \mathrm{m}$, the change in $\alpha$ was large, and within a certain range of values, $\alpha$ became negative, meaning stable, damped vibration. In this case, there was an optimum value which minimized $\alpha$ to $k_{s}$ and $C_{s}$. When $k_{m}=880 \mathrm{kN} \cdot \mathrm{m}, \alpha$ decreaed approximately linearly in relation to the increases in $k_{s}$ and $C_{s}$. For increases in $k_{s}$ and $C_{s}$ above certain levels, $\alpha$ became negative. $C_{m}$ had a large effect when $k_{m}$ was small, particularly for $k_{m}=88 \mathrm{kN} \cdot \mathrm{m}$; but it had only a small effect for $k_{m}=880 \mathrm{kN} \cdot \mathrm{m}$.

The conditions in Fig. 4( $\mathrm{i}$ ) matched those in Fig. 5 , point (1), while conditions in (ii) matched those of point (2). Results from simulations and eigenvalue analyses showed the same trend regarding the stability of the axle torsional vibration. The frequency, i.e. the imaginary part of the eigenvalue, was $94.7 \mathrm{~Hz}$ at (1) and $99.1 \mathrm{~Hz}$ at (2). This agreed closely with the simulations.

Table 2 shows the eigenvector values for axle torsional vibration at (1) and (2). The gearbox pitching component $l_{2} \theta_{s}$ was quite small when unstable, as at (1), and the gearbox seemed to be at the vibration node. The gearbox pitching component $l_{2} \theta_{s}$ was rela-

Table 2 Eigenvector values

\begin{tabular}{|l|l|l|l|l|}
\hline \multirow{2}{*}{ Variable } & \multicolumn{2}{|c|}{ Case $(1)$} & \multicolumn{2}{c|}{ Case } \\
\cline { 2 - 5 } & Value & Phase & Value & Phase \\
\hline$r_{\mathrm{p}} \theta_{\mathrm{m}}$ & 0.0027 & $1.37 \mathrm{deg}$ & 0.0068 & $180 \mathrm{deg}$ \\
\hline$r_{\mathrm{p}} \theta_{\mathrm{c}}$ & 0.632 & -180 & 0.986 & 0.001 \\
\hline$r_{\mathrm{p}} \theta_{\mathrm{p}}$ & 0.631 & -180 & 1.00 & 0.0 \\
\hline$r_{\mathrm{g}} \theta_{\mathrm{g}}$ & 0.695 & -180 & 0.572 & -35.5 \\
\hline$r_{\mathrm{g}} \theta_{\mathrm{w}}$ & 1.00 & 0.0 & 0.755 & 142 \\
\hline$r_{\mathrm{g}} \theta_{\mathrm{w} 2}$ & 0.875 & -180 & 0.727 & -35.1 \\
\hline$\ell_{2} \theta_{\mathrm{s}}$ & 0.0086 & -2.79 & 0.835 & 31.5 \\
\hline
\end{tabular}

tively large when stable, as at (2). Thus at (1), the gearbox suspension rubber spring had almost no effect on suppressing torsional vibration, while at (2), the gearbox suspension rubber spring suppressed it.

\section{Experimental Tests}

\section{1 Self-excited vibration during slippage}

Tests were carried out at the Mito Works, of Hitachi Ltd., using a test car accelerated under power. The test car had trucks that consisted of $130 \mathrm{~kW}$ induction motors and parallel Cardan drives. The specifications of the drive system are as listed in Table 1. Three types of flexible couplings were used: the leaf spring coupling (types ( i ) and (ii) in Fig. 1) and gear coupling. In particlular, experiments with the leaf spring coupling included making changes in the gearbox suspension rubber spring and the diameter of the torsion shaft. Fig. 6 shows the experimental results when a hollow shaft traction motor and leaf spring coupling type (i) were used.

Figure $6(i)$ gives the results for axle No.1, which had a torsion shaft diameter of $46 \mathrm{~mm}$ and used natural rubber for the gearbox suspension rubber spring (equivalent to (1) in Fig. 5), and on axle No. 2, which had a torsion shaft diameter of $52 \mathrm{~mm}$ and used natural rubber for its gearbox suspension rubber

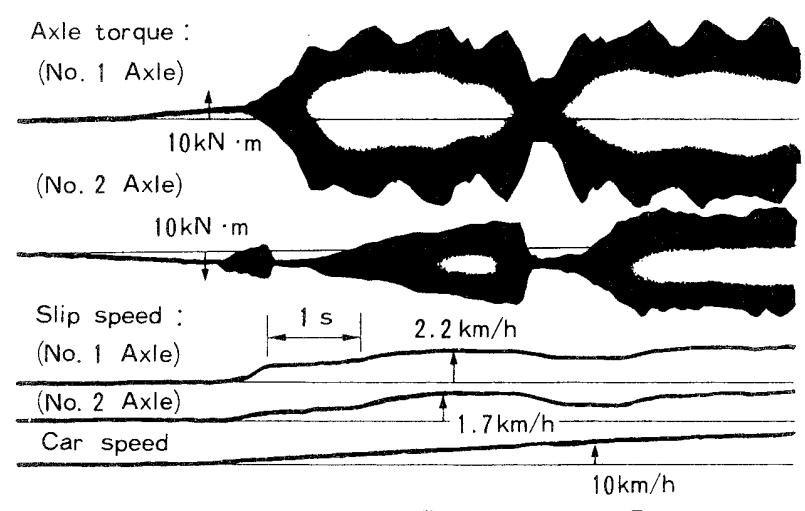

(i) No. 1 Axle: (1), No. 2 Axle: 3

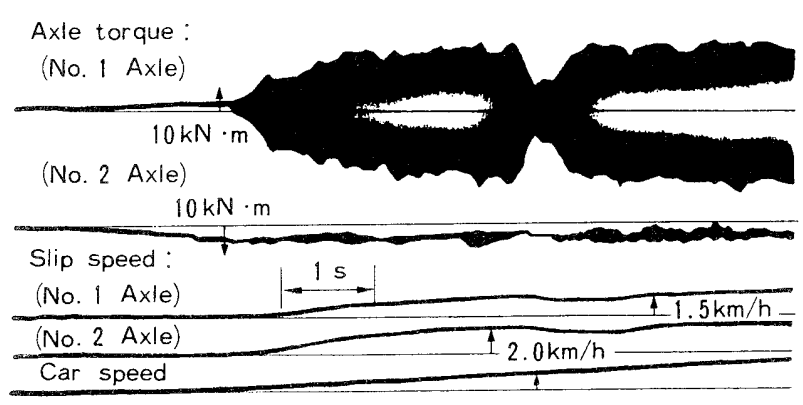

(ii) No. 1 Axle: (4), No. 2 Axle:?

Fig. 6 Experimental results on leaf spring coupling type (i) 
spring (3)).

The experimental results were in agreement with those of the eigenvalue analyses, and showed the occurrence of self-excited axle torsional vibration for both axles. Note that the frequencies derived by eigenvalue analyses were $97.5 \mathrm{~Hz}$ for (1) and $99.2 \mathrm{~Hz}$ for (3), while the experimental results gave corresponding values of $92 \mathrm{~Hz}$ and $94 \mathrm{~Hz}$.

Figure 6 (ii) shows results for axle No. 1, which had a torsion shaft diameter of $46 \mathrm{~mm}$ and the gearbox suspension rubber spring made from styrene butadiene rubber (SBR) (4) in Fig. 5), while axle No. 2 had a torsion shaft diameter of $52 \mathrm{~mm}$ and the gearbox suspension rubber spring of SBR((2)). As with the results from eigenvalue analyses, (4) showed the occurrence of self-excited axle torsional vibration, but it was suppressed with (2). The frequencies derived by eigenvalue analyses were $97.4 \mathrm{~Hz}$ for (4) and $99.1 \mathrm{~Hz}$ for (2) ; and from experiments, $93 \mathrm{~Hz}$ and $95 \mathrm{~Hz}$, respectively.

Figure 7 shows experimental results on slippage at start-up using type (ii) which had a solid shaft traction motor and leaf spring coupling. Figure 7 (i ) is for the natural rubber gearbox suspension spring (5) in Fig. 5) and Fig. 7 (ii) is for SBR (6)). Although different trucks were used, they had nearly the same parameters as those in Table 1. Since the drive power source was different, the slippage increased over that in the other experiments.

Figure 8 gives the experimental results when a gear coupling was used along with the natural rubber gearbox suspension spring jn axle Nos. 3 and 4 (estimated to be equivalent to (7) in Fig. 5, as discussed
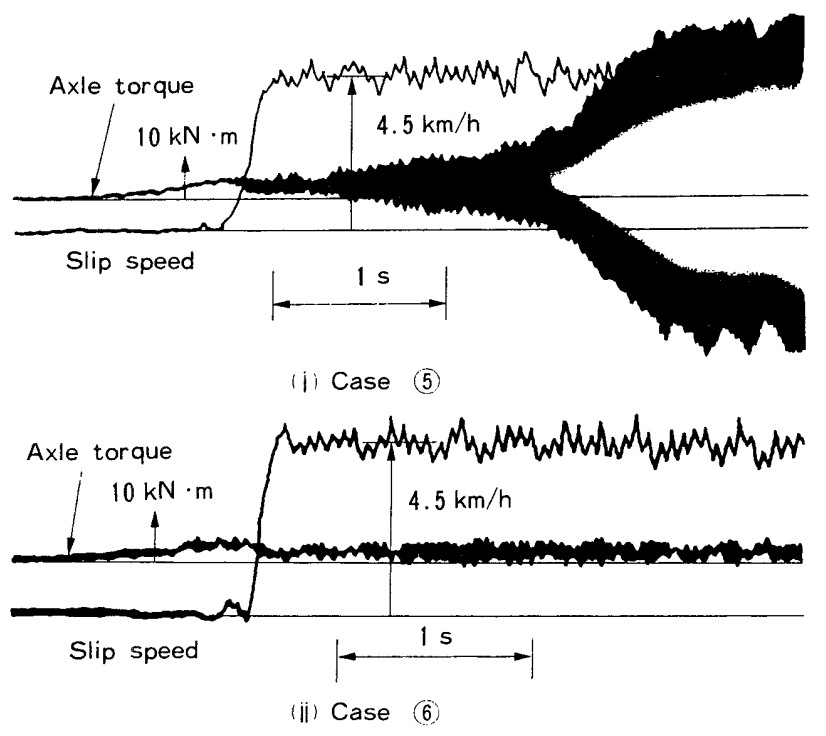

Fig. 7 Experimental results on leaf spring coupling type (ii) later). In this instance, there was no generation of self-excited axle torsional vibration. In explaining these results, it must be assumed that the spring constant $k_{m}$ of the motor rotor shaft was equivalently low and that the damping coefficient $C_{m}$ was comparatively large. This would be acceptable, if play and damping within the gear coupling were considered.

\subsection{The effect of self-excited vibration on the} available adhesion coefficient

The available adhesion coefficient was measured when the self-excited axle torsional vibration was generated, and when it was not.

The available adhesion coefficient $\mu_{a}$ is one of the values required for evaluating adhesion performance, and it is defined as the ratio between the average total tractive effort and the total driving axle load. In these experiments, the reference value for the traction motor torque was kept constant, and the average acceleration was measured when the car was accelerated from $5 \mathrm{~km} / \mathrm{h}$ to $25 \mathrm{~km} / \mathrm{h}$. Then, the available adhesion coefficient was derived by the following equation.

$$
\mu_{a}=\frac{\left(\alpha_{m}+\beta_{0}\right) W_{t}}{W_{a}} \times 100
$$

In this equation, $\alpha_{m}$ is the average acceleration $\left(\mathrm{m} / \mathrm{s}^{2}\right), \beta_{0}$ is the natural deceleration (actual measured value $=0.033 \mathrm{~m} / \mathrm{s}^{2}$ ) attributable to mechanical loss, $W_{a}$ is the total driving axle load $(N)$ and $W_{t}$ is the total mass of the test car $(\mathrm{kg})$, taking into consideration the rotating mass.

Each truck was driven independently, and $\mu_{a}$ was measured on the hollow shaft motor and leaf spring coupling of the truck (first truck) at the end of the test car which was in a state where self-excited axle torsional vibration was being generated, and on the gear coupling of the other truck (second truck) which was in a state where self-excited axle torsional vibration was not being generated. Thus $\mu_{a}$ was derived for each truck. To make sure that rail surface conditions were the same, water was sprayed on the rails and both trucks were run back and forth over the same

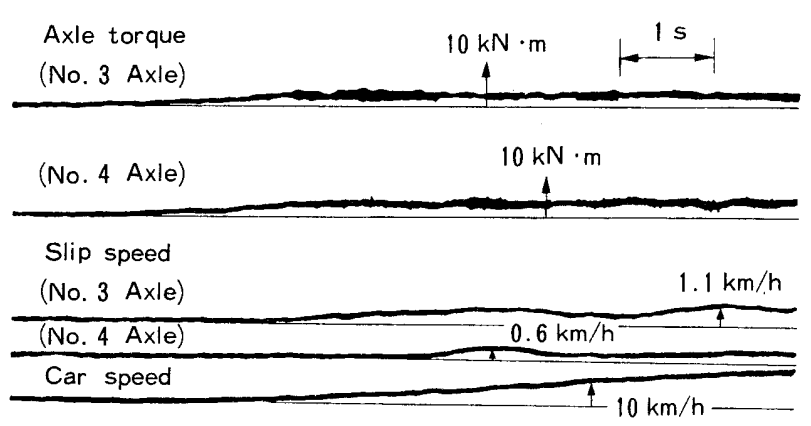

Fig. 8 Experimental results on gear coupling 


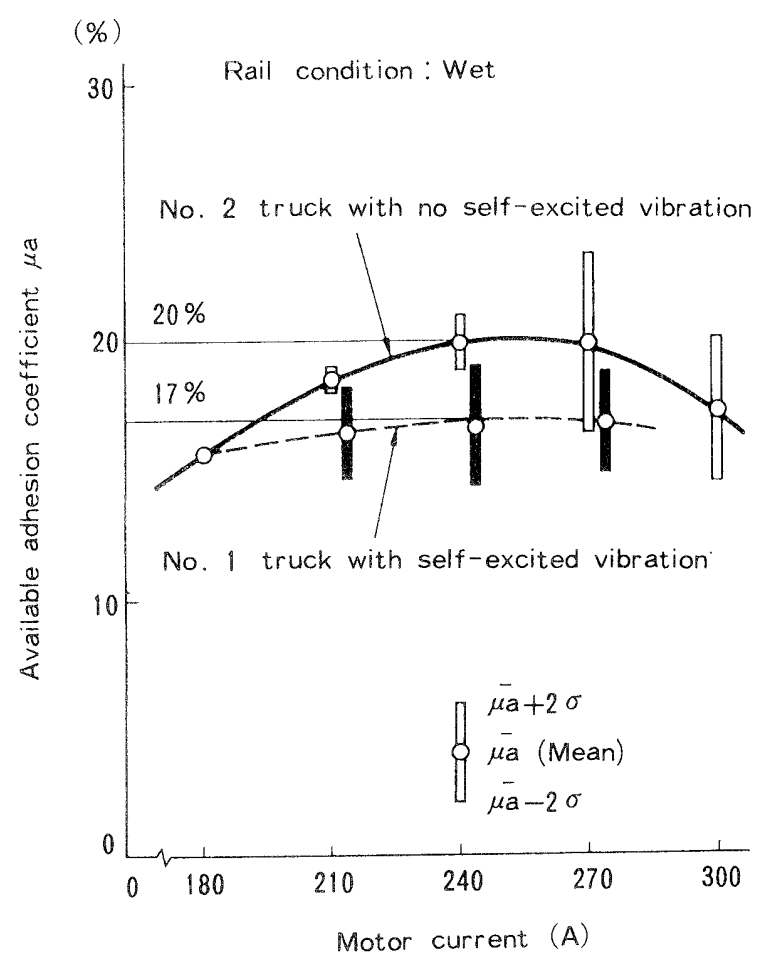

Fig. 9 Test results on available adhesion coefficient

section of track.

Figure 9 summarizes all the experimental results. The value obtained for the available adhesion coefficient for the second truck, which was not generating self-excited vibration, was about $20 \%$, while that for the first truck was about $17 \%$. The results were obtained from about 30 trials, and considerably more data would be required if fluctuations in the adhesion coefficient were taken into consideration. However, suppressing self-excited vibration was clearly desirable from the viewpoint of improving adhesion performance.

\section{Conclusion}

Theoretical and experimental studies were made on the self-excited vibration during slippage for repre- sentative parallel Cardan drives used in electric railcars. Experiments on the effects of self-excited vibration on the available adhesion coefficient were also carried out. The major results are as follows.

(1) Self-excited axle torsional vibration occurred easily when a hollow shaft traction motor, leaf spring coupling and a torsion shaft of small diameter were used. One of the effective ways to suppress the vibration was to increase the diameter of the torsion shaft and select a gearbox suspension rubber spring with appropriate stiffness and loss factor.

(2) Using a solid shaft traction motor and leaf spring coupling and increasing the stiffness and loss factor of the gearbox suspension rubber spring resulted in suppression of self-excited axle torsional vibration.

(3) The use of a gear coupling made the generation of self-excited axle torsional vibration difficult. This was attributed to the equivalently low spring constant of the motor rotor shaft and the occurrence of damping in it.

(4) Measured results showing that the absolute values of the available adhesion coefficient were approximately $3 \%$ higher when self-excited axle torsional vibration was not generated than when it was. This showed that suppression of the self-excited vibration was also desirable for better adhesion performacne.

The authors would like to thank their colleagues at the Mito Works and Kasado Works of Hitachi Ltd. for assistance and guidance.

\section{References}

(1) Nouvion, F. F., Railway Gazette International, Vol. 133, No. 9 (1977), p. 336.

(2) Bauer, H. P., Pfeiffer, R. and Hahn, K., Elektrishe Bahnen, Vol. 84, No. 2 (1986), p. 43.

(3) Körner, E., ZEV-Glaz. Ann., Vol. 101, No. 8, 9 (1977), p. 348.

(4) Hirotsu, T., and Ishida, S., Bull. JSME, Vol. 18, No. 125 (1975), p. 1236. 